\title{
A PARANOIA DO NEGRO NO BRASIL, A ANÁLISE DE ARTHUR RAMOS: UMA RELAÇÃO ENTRE IDENTIFICAÇÃO, CRIME E PUNIÇÃO
}

\author{
João Ezequiel Grecco ${ }^{1}$
}

\section{Resumo}

Neste artigo, propomos expor e discutir a construção teórica do médico e psiquiatra alagoano Arthur Ramos de Araújo Pereira (1903-1940), que estabeleceu relações entre os fatores de degenerescência e miscigenação na paranoia do Negro no Brasil, inter-relacionada com o processo da identificação, crime e punição. Em um primeiro momento seguidor da escola fundada pelo médico maranhense Raimundo Nina Rodrigues (1862-1906), professor da faculdade de medicina da Bahia, na qual o processo das anormalidades mentais residia no fator da miscigenação, isso é, a mistura consanguínea entre Negros, brancos e Índios, e a degenerescência. Seria atribuído fatores de violência e crime baseada em consequências na qual as condições da degenerescência, proposta teórica de Cesar Lombroso (1835-1909) e a teoria atávica de Tanzi e Riva, determinavam ao Negro um caráter de anormalidade mental paranoico onde as condições do crime e a violência seriam diretamente vinculados. Ao traçar nesse artigo os aspectos teóricos dados por Arthur Ramos no conceito de paranoia do Negro e sua relação com o crime e punição, de outra feita suas tentativas de enfatizar não só a singularidade do Negro, mas de formular o conceito do Inconsciente Folklórico. Uma pergunta fara parte desse trabalho; em que condição na contemporaneidade ainda seria possível levar em consideração as condições do Negro no Brasil e a relação da paranoia como catástrofe social, entre a constituição da paranoia como categoria clínica e a experiencia estética social de crise, isto é, da transformação.

PALAVRAS-ChAVE: Degenerescência. Miscigenação. Paranoia. Negro. Psicanálise.

\footnotetext{
${ }^{1}$ Psicanalista. Professor e supervisor clínico no Centro Universitário de Santo André na faculdade de Psicologia e de enfermagem, professor visitante e supervisor da residência médica e psiquiatria da Faculdade de Medicina do ABC e do Centro de Estudos Psicanalítico (CEP). Pós Doutorando - Instituto de Psicologia da USP sob a orientação do prof. Dr. Christian Ingo Dunker. Participante do LATESFIP (Laboratório de Teoria Social, Filosofia e Psicanálise - USP). Doutor em Psicologia social e mestre em Psicologia clínica (bolsista CAPES) pela PUCSP. Especialista em Psicoterapia do adolescente e do adulto pelo Instituto Sedes Sapientiae. Professor da Pós-Graduação em Psicanálise do Centro Universitário Anhanguera de Santo André (Unia). E-mail: jegrecco@usp.br. ORCID: http://orcid.org/0000-0002-2079-0404
} 


\title{
A DINÂMICA DA ESCRAVATURA NO BRASIL E SUAS CONSEQUÊNCIAS CONTEMPORÂNEAS
}

\begin{abstract}
Portanto, o que conheciam disso no plano do etnógrafo era mais ou menos como no do jornalismo, mas seus inconscientes funcionavam segundo as boas regras do Édipo. Era o inconsciente que tinham vendido a eles ao mesmo tempo em que as leis da colonização, forma exótica, regressiva, do discurso do mestre, frente ao capitalismo que se chama imperialismos. (LACAN, 19691970).
\end{abstract}

Para entender as relações dinâmicas da escravatura no Brasil e suas consequências antes e após o ato da lei da libertação, torna-se de fato necessário entendermos a ideia da corrente do pensamento antropológico, entre o evolucionismo cultural e o particularismo histórico, desde meados do século XIX até a década de 1930, o que coincide com a análise de Arthur Ramos a respeito da paranoia do Negro no viés da miscigenação e da degenerescência.

Se a teoria do evolucionismo cultural esteve impregnada do conceito da hereditariedade e da moral, entre meados do século XIX até o início do século XX essa teoria se constatava na dimensão das relações entre colonizadores e colonizados. Por outro lado, o conhecimento dos aspectos das sociabilidades de determinados grupos colonizados, nos quais crenças e estilos de vida tornaram-se de fundamental importância para o êxito de exploração praticada por colonizadores em território estranhos, estabelece as relações de poder sobre o outro.

Os evolucionistas (Spencer, Taylor e Morgan) baseavam-se na noção de que as sociedades não europeias poderiam ser configuradas como grupos inferiores na escala social. Esses grupos poderiam evoluir, mas ao longo de muito tempo, e com isso haveria um desdobramento na teoria evolucionista clássica (tomada pela análise de Morgan) na compreensão do pensamento cultural da época, ou seja, considerar a unidade psíquica do homem e a ideia de sobrevivência.

No Brasil isso ocorreu na exploração da mão de obra escrava do índio e do Negro, desta maneira não se acreditava na desigualdade psíquica entre indivíduos e entre grupos, mas sim em uma unidade. Por outro lado, o sentido de sobrevivência emoldura em objetivar e explicar certas tradições antigas e de difícil compreensão para sociedades consideradas mais desenvolvidas, visto que permaneciam em grupos sociais mais evoluídos e assegurava de certa maneira a evolução cultural do elo com o 
passado, sendo que os requisitos indicariam de certa maneira a trajetória das sociedades na linha evolutiva.

Inaugurou-se, então, uma metodologia de análise segundo a qual o conteúdo comparativo busca características semelhantes de diversas sociedades, comparandoas com a sociedade europeia, ou seja, em que medida e nível na escala evolutiva civilizatória o outro se situaria na relação enquanto grupo social. Assim, ao adotar esse viés, o método comparativo se baseava numa história unilinear, na qual fenômenos semelhantes ocorreriam no mundo em razão de causas semelhantes, desconsiderando os processos históricos internos de cada sociedade e até mesmo ignorando as causas dessa sociedade. Esse é o motivo pelo qual, no Brasil, o índio, tratado como "coisa", não comungava a eucaristia cristã implantada pela ação da exploração portuguesa e sua cultura não possuía peso, sendo por isso tomado como escravo; o Negro, por sua vez, mostrava-se como estrangeiro, já vinha escravo das colônias da África ou feito escravo nas lutas tribais que viam na escravidão um meio de comércio.

Para que o método de investigação se mostrasse consistente consideravam-se as descrições de viajantes, missionários e jesuítas - no Brasil houve, nesse caso, uma enorme expansão com a Companhia de Jesus - a respeito das regiões e sociedades nas quais estavam interessados. De fato, há um problema nessa forma de análise: a credibilidade, que se baseava na similitude dos fatos relatados dada pela impossibilidade de os narradores saberem o que era descrito entre eles, em virtude das razões geográficas.

Assim, as sociedades não europeias, consideradas selvagens, poderiam ser parâmetro ao entendimento do funcionamento da sociedade em seu princípio, ainda que os evolucionistas imaginassem que os selvagens contemporâneos o seriam semelhantes aos primeiros homens, aqueles eram representados como o mais próximo que se poderia chegar de uma compreensão sobre o assunto (SOILO, 2014).

Nessa análise em que os evolucionistas abordam tal conceito de selvagens, haveria o contraponto com a sociedade europeia. A isso convém destacar a proposta de Lewis Morgan em seu livro Systems of Consanguinityand Affinityofthe Family, publicado em 1871, no qual há referências de parentesco a influenciar as relações nos grupos sociais, as relações de ocupação do solo e as relações de propriedade. Dessa maneira, faceia o entendimento das relações sociais humanas como unilinear, nas quais toda a sociedade estaria fadada a passar pelas mesmas etapas do desenvolvimento e com isso poder-se-ia enfatizar a noção de que a sociedade dita 
humana passaria pelas seguintes etapas: selvageria, barbárie e civilização. A selvageria antecederia a barbárie e, por fim, a civilização de modo natural e inexorável. Os estágios se relacionariam entre si a partir da ideia do progresso inevitável cujo parâmetro consistiria no modo de vida europeu da época (SOILO, 2014).

No Brasil, a dinâmica da escravidão se serviu da visão evolucionista como um elemento a substantivar e justificar a escravatura. Para as cortes de Portugal as experiências em Angola e Moçambique legitimaram sua implantação na monocultura da cana-de-açúcar e, dessa maneira, foi dado ao negro um estatuto de desterro, sem lugar, sem identidade, sem retorno à origem, cujas condições resultam na implantação, sem resistência, da exploração da mão de obra escrava. Para esse fim, houve uma intensa relação com o tráfico negreiro transatlântico no período, o que suscitou padrões de alforria e oportunidades de resistências escravas coletivas, nas quais almejavam alçar a liberdade, fruto de uma sistemática de força e poder em desordem na ocasião.

Se a tônica do sistema escravista brasileiro se deu na estreita relação entre o tráfico transatlântico de escravos (bastante volumoso) e o número constante de alforrias, essa lógica possibilitou aumentar a intensidade do tráfico sem comprometer a ordem social escravista. Assim, as revoltas dos escravos foram sufocadas sem nenhum termo de negociação por parte das autoridades coloniais portuguesas, com a garantia de continuidade da escravatura. De fato, as revoltas foram coletivas, o que representou a forma mais radical de contestação da escravidão, sem, todavia, que toda revolta almejasse destruição do regime escravocrata. Muitas buscavam apenas corrigir o excesso de tirania senhorial, diminuindo até um limite tolerável a reconquista de ganhos perdidos ou punindo feitores e senhores particularmente tirânicos (REIS apud SCHWARCZ; GOMES, 2018).

Portanto, as condições expostas até aqui sustentam a dinâmica da escravatura: a mão de obra necessária no Brasil colonial. Diante disso ousaríamos afirmar a coexistência de um regime escravocrata e de um sistema capitalista. Nesse sentido, abrimos breve discussão, visto que nosso tema considera a condição do Negro e as anomalias psíquicas postas como signatárias da miscigenação e da degenerescência apontadas no negro, no qual o crime e a punição estariam na ordem determinista de um sistema capitalista, que, por sua vez, não promoveu laços sociais, pois no período do Brasil Colônia o Negro não possuía nada (salário e poder de consumo) a não ser sua força de trabalho. 
Além disso, no Brasil não houve uma revolução burguesa. O país sempre se consolidou capitalista desde os tempos coloniais, mas o sistema capitalista necessita de uma economia na qual se estabeleça uma demanda interna de consumidores, sendo tais consumidores elementos de um meio de produção no qual haja condição de trabalho livre e assalariado. Para as condições brasileiras, isso ocorreu com a entrada de mão de obra imigrante, que substituiu o escravo negro nas fazendas de café, passando o imigrante a corresponder à máxima do capital: assalariado e consumidor, fatores fundamentais para o desenvolvimento do capitalismo.

Há dois momentos que de certa maneira contribuíram para a formação do capitalismo no Brasil: a independência do Brasil como um marco histórico em que o país deixa de lado a condição da era colonial e a formação de uma sociedade nacional; e a substituição da mão de obra escrava pela do imigrante assalariado, o que propiciou a dimensão de um sistema capitalista que perdura até a contemporaneidade.

Se o trabalho do escravo se tornou necessário para a colônia, pelo fato de não haver mão de obra suficiente nem na colônia nem na metrópole, esse fato representou lugar-comum nas colônias portuguesas e espanholas, pois a utilização de mão de obra branca não se mostrou, a princípio, ponto a ser levado a sério. Tanto o índio na construção dos engenhos de açúcar quanto o negro na lavoura de café forneceram à colônia a dimensão que a corte de Portugal almejava: a exploração natural de uma monocultura e uma mão de obra que servia a seus interesses.

Portanto, com desenvolvimento de uma monocultura (a cana-de-açúcar), sua crescente demanda na produção e a ausência de mão de obra livre, a utilização do trabalho escravo atendeu as necessidades do momento. Fato que atrelava a produção brasileira aos centros europeus consumidores que aumentavam a demanda como também intensificavam o tráfico escravo. Ora, se a condição do capitalismo reside na "exploração" do trabalho assalariado pelo capital, como essa condição não existia no Brasil Colônia, logo, não haveria o capitalismo no Brasil Colônia. Não necessariamente.

O fato é que a mão de obra escrava, explorada pelo capital, gerava e aumentava os lucros, características que determinaram o tipo de exploração agrária, ou seja, uma monocultura lucrativa a atender um mercado externo (PRADO JUNIOR, 1980). O que se constata é, sim, um trabalho livre e assalariado, raro que fosse, mas vinculado aos mestres-do-açúcar e à parte de uma elite na administração do tráfico escravo.

Por fim, essa dinâmica escravocrata se decompôs por tantas alforrias, nas quais o Negro conseguia a condição de "estar livre", porém sem sair do Brasil e tampouco 
tornar-se alguém diferente, a não ser adquirir um pedaço de terra e também alguns escravos $^{2}$.

Assim, em 1850, com a lei que proibia o tráfico de escravos, não tardaria a Abolição. Em 1888, finalmente abolia-se a mão de obra escrava e instaurava-se o regime de trabalho livre. Houve, para o Negro, sua devida libertação; no entanto, haveria outra escravatura, agora pelo poder de vigilância e castigo, visto que ele não possuía aptidões a não ser desempenhar a função de escravo. Nessa condição, o Negro encontrava-se despreparado para competir com os imigrantes que detinham a técnica agrícola, se organizavam em grupos e, além disso, eram letrados, poucos, mas letrados.

Nessa nova sociedade burguesa a despontar (não só por meio da cana-deaçúcar, mas também do café), os primórdios de um desenvolvimento industrial e a estratificação das classes (por profissão, saber, cor, miscigenação e o conceito da degenerescência, ainda fortemente influenciado pelos países "desenvolvidos" europeus) constituirão um dos tópicos a nortear de certa forma a higienização a ser levada a cabo na sociedade brasileira após a escravatura; além da influência determinante da ciência médica europeia - que estabelecia na degenerescência e na miscigenação fundamentos antecipatórios ou justificáveis para o crime e a punição -, segundo a qual a hereditariedade e as relações familiares legitimavam esse dispositivo.

\section{A Noção de Degenerescência e a Miscigenação: Hereditariedade e Moral}

No Brasil, a miscigenação mostra-se implícita desde a chegada dos europeus e suas relações com o Índio, e posteriormente com o Negro. Outro fator dessa lógica binária apresenta-se na história da degenerescência e suas relações com a hereditariedade e a moral, o que, de certa maneira, apontaria de forma estigmatizada a relação do Negro com o crime e a punição.

A publicação, em 1857, do Traité des Dégénérescences, de Benedict-Augustin Morel, revela que a teoria da hereditariedade dos transtornos mentais estabelece uma relação com a proposição religiosa católica, segundo a qual o homem teria sido criado, na perfeição, por Deus. Desse modo, a degeneração seria correlata ao pecado original, assim constituindo a transmissão para a descendência de taras, vícios (álcool, jogo,

\footnotetext{
${ }^{2}$ A lei do Ventre Livre, de 1871, contempla os jovens nascidos após essa data e maiores de 21 anos para sua total liberdade.
} 
prostituição etc.) e traços da morbidez adquiridos pelos antecessores, que, conforme passassem de geração a geração, tenderiam à completa desnaturação dessa linhagem (PEREIRA, 2008).

No Brasil, na relação da colonização, tanto o Índio como o Negro sofreram um longo processo de catequese, entendida então como a conversão dos gentios, dos que não possuíam alma, sem pecado original. Isso possibilita atribuir a essas culturas que advogam crenças outras, no caso do catolicismo, condições da hereditariedade biológica e moral. E, correlato a isso, a noção de que haveria um fator biológico de natureza hereditária estabelecia uma contingência relevante na etiologia dos transtornos mentais, o que se constata desde os primórdios da psiquiatria contemporânea.

Os elementos hereditários compõem a ideia de que haveria predisposição a esses fatores perturbadores, sendo que o Negro estaria na condição desse estigma determinante e, além disso, fora dos preceitos da moral. Pinel destaca de forma significativa esses fatores em seu Traité médico-philosphique surl'aliénationmentale, de 1801, influenciando outros autores nessa mesma linha de pensamento, como JeanÉtienne Esquirol e Jean-Pierre Falret. Com isso, as predisposições às perturbações morais e à loucura assumiam uma perspectiva de traços transmitidos por gerações familiares. Nesse caso, o Negro estaria a responder a todo tipo de implicância dimensionada pela hereditariedade ou pela moral.

Morel esforçou-se significativamente na tentativa de uma nosografia psiquiátrica fundada na concepção da etiologia natural dos transtornos mentais, buscando uma unidade entre o quadro clínico e os aspectos da evolução e a causa biológica de cada entidade diagnosticada. Mas existiam algumas questões que esbarravam em formulações deterministas e pragmáticas, visto que as ideias morelianas apontavam na direção das degenerescências, às quais se vinculavam a pluralidade, isto é, repousam na concepção de que a herança transmitida através das gerações não se restringia somente ao plano biológico, mas também às dimensões morais e do comportamento, sejam virtuosos ou viciados. Entre as características atribuídas ao Negro por causa de sua condição miscigenada, temos, por exemplo a afirmação de não serve para nada, apenas para ser serviçal, pois sua constituição moral apresenta-se degenerada e por isso ele não reconhece as etiquetas da sociedade.

A degenerescência, sob a ótica de Morel, suporta várias condições causais (e que se associam à noção de uma posição paranoica em relação ao Negro), entre as 
quais podemos destacar: o alcoolismo, a alimentação deficiente e diferente, o meio social miserável, e não poderíamos excluir as relações de parentescos familiares, em particular, o infante.

A pluralidade a que nos referimos, isto é, a ênfase segundo a qual as condições hereditárias assumiriam papel relevante, não só nos complexos familiares, mas sem dúvida nas condições da criança, que, por sua vez, encarnaria a anormalidade (FREUD, [1893-1899] 2006), possui a mais árdua intenção em estabelecer as condições da influência dos aspectos hereditários.

A condição na qual a patologia nervosa deve ser vista sob a ótica da hereditariedade assenta-se na condição da hereditariedade similar, em que os aspectos hereditários possuem em si fator primordial, a exemplo da miopia, da síndrome de Down etc. Por outro lado, a hereditariedade dissimilar, que seria mais relevante que a outra, deixa lacunas que deveriam ser satisfeitas antes que se pudesse chegar a uma solução satisfatória dos problemas etiológicos.

Nessa perspectiva, a hereditariedade dissimilar aponta que os membros de uma mesma constelação familiar podem ser afetados pelos mais diversos distúrbios nervosos, funcionais e orgânicos - aliás, sem que se possa constatar qualquer lei que determine a substituição de uma doença por outra ou de sua sucessão entre gerações. O que se constata é que nesses complexos familiares haveria membros saudáveis. Ora, a teoria da hereditariedade dissimilar não nos diz porque uma pessoa tolera a mesma carga hereditária sem sucumbir a ela, ou porque outra pessoa, doente, é acometida por uma afecção nervosa específica, dentre todas as doenças que compõem a grande família das doenças nervosas, em vez de outra: a histeria no lugar da epilepsia ou a psicose no lugar de algo qualquer (FREUD, [1893-1988] 2006).

A posição freudiana nesse sentido mostra que as condições dos fatores hereditários na análise e no diagnóstico das doenças nervosas exerceram enorme influência na tentativa de Arthur Ramos em desvincular a hereditariedade e a degenerescência do Negro no Brasil. Por outro lado, constatamos em Freud o esforço de separação, nesse sentido, ao lançar mão de uma inovação nosográfica, pondo lado a lado a histeria e a neurose obsessiva, como distúrbio autossuficiente e independente, constatando que a maioria das autoridades situava as obsessões entre as síndromes constitucionais da degenerescência mental ou as condutas como a neurastenia (FREUD, [1983-1988] (2006). 
Se os complexos familiares se condicionavam sob o julgo de anormalidades, independentemente sob quais tipos se apresentassem, as crianças (frutos dessas anomalias) talvez pudessem ser confinadas em asilos ou reformatórios. No Brasil, e em particular com o Negro após a escravatura, esse recurso não só antecipava atos transgressivos como também justificava o que a degenerescência sedimentava, ou seja, que as crianças mais ou menos débeis do ponto de vista intelectual sofriam de perversões dos instintos: ladrões, mentirosos, homossexuais, homicidas etc (FOUCAULT, 2006).

O poder da psiquiatria não se restringiu apenas ao saber. Ultrapassou muito além disso e, na contemporaneidade, não se faz de outra maneira, visto tudo o que se avalia como anormal em relação à disciplina escolar, militar, familiar etc. Será reivindicado pela psiquiatria como a condição de fazer ortopedia no mal-estar do sujeito.

Portanto, a noção de degenerescência e todas as consequências que se possam atribuir como anormalidade, encontrava na criança a anomalia produzida pelos pais. E, por outro lado, a criança degenerada consiste numa criança anormal, cuja anomalia é tal que pode produzir, em certo número de circunstâncias determinadas e após certo número de acidentes, a loucura.

Dessa maneira, a degenerescência configuraria a predisposição para lançar mão do conceito de anomalia. Na criança tornar-se-á possível a loucura do adulto e, além disso, demarcará os complexos familiares. Tomados em bloco e sem definição bem estrita, a criança fará desse duplo fenômeno - a anomalia e a loucura - o suporte coletivo que é a família (FOUCAUT, 2006).

$\mathrm{Na}$ análise do Negro e de suas condições sociais após a escravatura, os fatores da degenerescência, associados à noção da miscigenação, estabeleceram como sentido que as anormalidades apontavam para uma coletividade, que agora deveria se inserir no complexo social. Todavia, esta não tinha construído um percurso histórico e tampouco contribuíra para as relações sociais. Ou seja, o Negro, ao deixar de ser "coisa" escravo passa a ser anônimo, não possui função social a não ser fazer o que sempre fez, "servir" para qualquer coisa.

Haveria um peso nisso tudo ou pelo fator da hereditariedade implicada nos complexos familiares, como já salientamos, ou nos imperativos morais, visto que sobre o Negro pairava em sua dimensão uma ideia paranoica de que a sociedade deveria estar prevenida, porque ele mostrava-se inconsistente, anormal, sem cultura e alheio aos costumes sociais que valorizavam ou que se esperava que o fizesse. A todos esses 
fatores, que a psiquiatria tomará em seu poder, Arthur Ramos dará outro fundamento e configuração ao convocar a psicanálise e a psicologia social na análise das condições do Negro e de sua estigmatização - a condição paranoica da degenerescência e da miscigenação - que pudesse desvincular o crime e a punição.

\section{O Pensamento De Arthur Ramos na Análise da Degenerescência e da Miscigenação COMO CRIME E PUNIÇÃo}

Arthur Ramos (1903-1949) foi um médico alagoano que se destacou em várias esferas do saber, entre elas a Psicanálise, a Criminologia, o Folclore, a Antropologia e a Psicologia Social. Dentre esses percursos aos quais se filiou analisemos a psicanálise a partir da qual Arthur Ramos fez suas primeiras e intensas articulações.

As ideias da psicanálise aportaram no Brasil em meados do século $\mathrm{XX}$ e, com isso, o estudo e a difusão de seus conceitos abrangeram um número significativo de psiquiatras e artistas, em particular aqueles engajados ao Movimento Modernista, do qual derivou a Semana Modernista, em 1922. No entanto, há uma ressalva quanto ao fato de que o discurso psicanalítico em sua essência, com relação a esses psiquiatras, ditos como percursores, não é considerado um discurso psicanalítico. Naquele momento havia um direcionamento segundo o qual a psicanálise oferecia como alternativa uma teoria moderna e científica para preceitos da moral tradicional, até então vistos como arcaicos e ultrapassados.

Assim, o discurso psiquiátrico e psicanalítico no Brasil no início do século $X X$ era marcado pela tentativa de conciliação de vários pontos de vista: a noção de doença mental e o comportamento do homem em geral. A colaboração dos médicos Juliano Moreira e Afrânio Peixoto na divulgação (e colaboração) da teoria de Emil Kraepelin, que defendia uma psiquiatria organicista, também contribuiu com a divulgação e a difusão da psicanálise (MENESES apud BARROS, 2010).

Arthur Ramos, no período em que viveu na Bahia, vinculou-se à psicanálise defendendo e divulgando tais teorias, publicando artigos sobre vários temas psicanalíticos e reunindo em torno de si um grupo que estudava a psicanálise. Ao acompanhar a trajetória de Arthur Ramos, observamos que a psicanálise servirá de instrumento a ser utilizada em vários campos de trabalho: na compreensão da loucura, da educação infantil e da cultura negra e, além disso, na descrição dos meios 
institucionais e na divulgação de seus trabalhos para a comunidade médica, em particular a dos psiquiatras baianos.

De outra feita, a psiquiatria no Brasil remonta os primórdios do século $X X$ e apresentava como principal referência a teoria organicista de um representante da escola alemã, Emil Kraepelin, que se opunha à escola francesa, calcada numa concepção moral da doença mental e enormemente difundida no Brasil. Nesse sentido, ao buscar identificar uma lesão cerebral ou uma etiologia baseada no paradigma bacteriológico que vinha dominando a psiquiatria nesse período, a miscigenação e a degenerescência também compunham as ideias dos psiquiatras brasileiros, que se aliaram à escola alemã.

Nesse aspecto, o médico brasileiro Raimundo Nina Rodrigues (1862-1906), em seu artigo La paranoia chez lesnégres (publicado em 1903 na revista francesa Archives d'AnthropologieCriminele, de Criminologieet de PsychologieNormale et Pathologique, de Lyon), marca uma longa influência na classe médica da época. Seu artigo versa sobre o conceito de paranoia e suas possíveis formas clínicas associadas aos atos violentos e criminosos, dentre os quais se destacam, de maneira ilustrativa, inúmeros casos clínicos usados na discussão da semiologia sobre a paranoia nos negros e mestiços brasileiros (ODA; DALGALARRONDO, 2004).

Raimundo Nina Rodrigues criou uma escola com larga influência na psiquiatria brasileira e na difusão de suas ideias e teve em Arthur Ramos seu representante mais fiel, que, por sua vez, divergiu de Nina Rodrigues e desenvolveu outra abordagem na compreensão da paranoia do Negro no Brasil. O médico Nina Rodrigues intentava demonstrar que a paranoia que incidia sobre os negros, em sua essência, suas manifestações, não diferia daquela vista nos brancos.

Nina Rodrigues divergia enfaticamente das ideias dominantes dos psiquiatras brasileiros que negavam ao conjunto de indivíduos de ascendência africana a capacidade cerebral ou o grau de desenvolvimento mental necessários para que apresentassem sintomas mais complexos, como a sistematização dos delírios e as manifestações clássicas da histeria. A influência de várias escolas psiquiátricas implicava em observações de perturbações mentais em não europeus, em raças primitivas e selvagens, ou em povos não civilizados, nos assim chamados estudos de psicopatologia, ou melhor, a psiquiatria comparada.

Destaca-se o relevante papel de Nina Rodrigues no cenário brasileiro e a consequência de sua posição multirracial, em particular do Negro, o que implicou no 
fato de Arthur Ramos também ser um estudioso dessa escola e seguir o que considerou relevante de toda a obra de Nina Rodrigues. No período de 1870 a 1930 estabeleceuse no Brasil uma larga produção intelectual e científica, em que as questões raciais e sociais foram largamente debatidas, visto que faziam coro a uma ideia da identidade nacional.

Não podemos deixar de apontar que, após a Abolição da escravatura em 1888, os entraves, os problemas, as queixas ou tudo o que fosse possível era direcionado aos negros e mestiços brasileiros. E, para dar suporte a essa ideia, evocava-se a ciência. Assim, a teoria da degenerescência e dos determinismos climático, racial e moral podiam responder a vários entraves, aos quais se agregava a miscigenação, ditando a ordem de fatores previamente determinados no crime e na punição.

Os pensadores e cientistas brasileiros viram-se obrigados a refletir sobre 0 futuro de um país mestiço num clima tropical. Ou seja, em tese, duplamente fadado ao insucesso, o Brasil ainda não encontrou de fato as suas condições da tristeza: ali numa terra radiosa vive um povo triste.

Legaram-Ihe essa melancolia os descobridores que a revelaram ao mundo e a povoaram. O esplêndido dinamismo dessa gente rude que obedecia a dois grandes impulsos que dominavam toda a psicologia da descoberta e nunca foram geradores de alegria: a ambição do ouro e a sensualidade livre e infrene que, como culto, a Renascença ressuscitara (PRADO, 2011, p.53).

No contraponto desse cenário, Arthur Ramos se afastou da escola de Nina Rodrigues e, influenciado pelo estudo e pela pesquisa da psicanálise, construiu suas análises a respeito da paranoia do Negro no Brasil. Suas pesquisas consideravam, de forma comparativa, o comportamento paranoico com o do homem primitivo, a partir do conceito de regressão. Suas convicções baseavam-se no fato de que haveria a construção paranoica independentemente se homem primitivo ou não. Seguindo o conceito da época, RAMOS (1926), em sua tese, apontava a seguinte expressão: "O selvagem dormita na alma de todo homem, vive à espreita de uma oportunidade para se entremostrar em seus caracteres bárbaros e antissociais, e com isso seria possível pensar na elaboração do conceito de inconsciente folclórico".

Esse apontamento faz jus a uma síntese das teorias de Freud, em particular seu artigo Totem e Tabu ([1912-1913] 2012); além dos conceitos de inconsciente de Carl Jung; de inconsciente intrapsíquico de Janet e Tarde; e não das influências da teoria do atavismo psíquico de Tanzi e Riva. Ramos pretendia formular o inconsciente 
folclórico e estabelecer uma interlocução freudiana, contida no texto Totem e Tabu, no qual haveria referências ao modo de transmissão das experiências ancestrais na transmissão de uma geração para outra.

A psicanálise possuía em seus conceitos razões para Arthur Ramos construir uma nova nomenclatura a respeito do Negro e das relações sociais, nas quais se apregoava uma forma imperativa da análise do crime e da punição. Ao se utilizar da psicanálise para sua formulação de análise das condições do Negro e das interrelações pertinentes ao crime e à punição, por sua vez, servira ao propósito da década de 1920, em que o programa de higiene mental defendido pela elite da psiquiatria acentuava sua intervenção na prevenção da doença mental das pessoas ditas normais e assim se valia do meio educacional, profissional e social como lugares privilegiados para esse fim.

Portanto, o papel do super-Eu, enquanto agente repressor dos impulsos antissociais, consistia em domesticar os instintos permitindo o convívio social. Arthur Ramos entendia que a psicanálise poderia ser aplicada na educação como instrumento de investigação dos processos inconscientes que poderiam interferir na formação da criança (BARROS, 2010). Assim, ao desdobrar a psicanálise em antropologia, entre os anos 1920 e 1940, Arthur Ramos teve na ciência a busca para compreender um contingente de sujeitos, que a partir daí estará à mercê de uma ciência ou de uma moralidade em que cor, raça, moral e atributos físicos ditariam uma análise prévia de persecutoriedade no crime e na punição.

Seu nome e o de Roger Bastide figuraram no ápice da produção de uma antropologia, igualmente influenciados pela literatura psicanalítica, porém com grandes contrastes em outros aspectos. Os autores antropólogos-psicanalíticos buscavam compreender como se organizava culturalmente o pensamento das camadas subalternas da sociedade brasileira, tendo como base uma característica genuinamente arcaica e primitiva, mesmo que os aspectos relativizassem, até certo ponto, as implicações evolucionistas lineares dessa caracterização. Dessa maneira, nos debates da época, se atribuía de forma inconteste o atraso do Brasil ao peso da raça Negra ou à sua herança (BARROS, 2010).

A década de 1930 representou, para o nosso autor, uma virada nos anais da antropologia, visto que fez desse saber o viés de análise do Negro no Brasil e as consequências desdobradas no que tange ao estigma: pobre, psicótico e preto. Sua publicação em 1934 do livro O negro brasileiro apresenta uma vasta pesquisa do Negro 
e sua cultura singular, que enfatiza o folclore (a razão de pensar o inconsciente folclórico), resultando em O folclore negro do Brasil (1935) e em As culturas negras do Novo Mundo (1936).

Sua aliança com a psicanálise e com as ideias de Lévy-Brühl favoreceram a interpretação dos mitos africanos, da música e da dança e do fenômeno da possessão, fato relevante em sua análise do Negro no Brasil ao elevar ao patamar de consignar ao sujeito, seja ele branco, ou Negro, sua dignidade de um sujeito do desejo e consequentemente de sua cultura e singularidade, posto que no momento de sua prática, o Negro estava sob o olhar da ciência médica psiquiátrica, com suas determinações e obscurantismo, para a qual a raça, a degenerescência, a moral e a hereditariedade civilizatória impunham às "sociedades primitivas" o julgo de conceitos pré-determinados de loucura, crime e degeneração.

A teoria evolucionista social era otimista em relação à possibilidade de um povo tornar-se civilizado (BARROS, 2010), porém, na análise de Arthur Ramos, essa miragem apresentava-se em outra ordem: procurar na religiosidade dos negros determinantes explicativos das manifestações psicológicas - ao comentar uma afirmação de Raimundo Nina Rodrigues de que a catequese junto aos negros não passou de uma mera ilusão - visto que eles aceitaram o catolicismo e suas práticas por causa de uma incapacidade psicológica de abstração, incorporando ao seu sistema a relação mítico-religiosa.

Se a incapacidade psicológica de abstração está vinculada a um conceito psicológico e sociológico, é, sim, a função da mentalidade primitiva, caracterizada pelo pensamento simbólico, percepção mística e representações coletivas. O que Ramos destaca consiste em que os mesmos tipos antropológicos brancos possuem uma mentalidade primitiva, como a criança e o selvagem, o adulto civilizado apresenta um tipo de mentalidade pré-lógica em certas ocasiões, como os sonhos, a arte etc.

Seja pela via da psicanálise (sua referência) ou da teoria de Lucien Lévy-Brühl, que o respaldará no entendimento da mentalidade primitiva, a mentalidade primitiva estaria submetida a um princípio oposto à contradição, sendo denominada como prélógica. Nesse sentido, Ramos advertiu de que a mentalidade pré-lógica não deve ser entendida como anterioridade no tempo, mas uma lógica diferente que se abstém da contradição (BARROS, 2010).

Em 1937, ao abandonar a teoria psicanalítica na tentativa da interpretação da cultura negra, sua mirada recaiu sobre o caráter social na inclusão do laço social do 
Negro e suas inter-relações entre o crime e a punição. Com seu livro Introdução à psicologia social, de 1935, o marco de sua passagem da psiquiatria à antropologia, demonstra o seu interesse em formatar na psicologia social as relações implicadoras culturais do Negro e sua relação com a noção do primitivo e da loucura.

Assim, fazia coro ao que defendeu em sua tese, na qual buscou ao longo de sua carreira como médico e pesquisador o reconhecimento, na psicanálise, de uma teoria que concebesse um substrato comum - o inconsciente e suas formas de manifestação - ao comportamento da criança, como do louco e homem primitivo. Ao lançar o inconsciente folclórico como medida de um entendimento das condições nacionais brasileiras da miscigenação da qual somos, desde sempre, constituídos, deve-se considerar a condição de uma paranoização na qual o Negro e todas as condições sociais marginalizadas - loucos, homossexuais, mulheres etc - fizeram (e fazem), na contemporaneidade, parte de instâncias de pré-julgamento: degenerados, miscigenados, imorais e presos à hereditariedade, o mal começa e não acaba para um grupo social, colocado do lado de fora das condições nas quais a burguesia se vê à mercê e ameaçada, isto é, tem de ficar fora essa gente diferenciada.

\section{CONCLUSÃo}

Nossa intenção, ao considerar o percurso do médico alagoano Arthur Ramos nas interfaces da psiquiatria, psicanálise, antropologia e finalmente da psicologia social, consistiu em traçar, pelo enunciado proposto, a paranoia do Negro no Brasil, após a escravatura, na relação do crime e da punição.

A contextualização sócio histórica que elaboramos serviu de substrato a fornecer ao leitor uma noção das condições do período escravocrata no Brasil e suas implicações nas relações de poder e vigilância, respondendo por um modelo capitalista vigente à época, no qual o mundo civilizado europeu tinha para si a noção narcísica de que só e apenas esse universo possuía saber e dignidade, na expressão de Fanon (1968, p. 42):

[...] o colonizado é sempre perseguido que sonha permanentemente em se tornar perseguidor..., e o psiquismo retrai-se, oblitera-se, despeja-se em demonstrações musculares que levam os eruditos a dizer que o colonizado é um histérico. Essa afetividade em ereção, espreitada por guardiões invisíveis, mas que comunicam sem transição com o núcleo da personalidade, vai comprazer-se com erotismo nas dissoluções motoras da crise. 
Estaria estigmatizado de uma certa maneira um traço paranoico do Eu Negro representativo muito aquém dos recursos e sem condição do desenvolvimento europeu, isto é, africano, escravo, sem cultura, biologicamente os fatores da degenerescência aliavam-se a esse binômio no qual Arthur Ramos realizou uma mudança de direção, aliando as condições psicológicas, individuais, culturais e antropológicas, desmistificando essa condição adotada pela ciência médica no Brasil em boa parte do século $X X$.

O Brasil se constituiu como um país miscigenado e sua hegemonia racial se compõem da mescla inicial de Índio, Negro e branco. Mas, para que a vigilância e o poder sustentassem a condição da escravatura haveria de classificar o Negro como primitivo, bárbaro e delinquente, despersonalizando-o para o sucesso e o domínio da mão de obra escrava. A ciência, fosse ela médica ou jurídica, valeu-se dessa condição para se basear nas conjecturas primitivistas de acordo com as quais o conceito de degenerescência apontaria as mazelas de uma cultura ainda sem conteúdo e despreparada frente à europeia.

Nesse ponto, por sinal, seguindo a escola psiquiátrica europeia, impuseram ao Negro toda uma ordem de classificações - o louco, o pobre, o marginal - desdobrada na condição de que o sujeito sob esse perfil atendia ao estigma do degenerado num tripé que se pode ampliar: pobre, psicótico e preto. Arthur Ramos buscou subverter essa análise e romper com a escola de Raimundo Nina Rodrigues no que se refere à condição da loucura, até então chamada paranoia.

Haveria, sim, uma paranoização do Negro, visto que ele não podia ser tratado em detrimento de sua condição da degenerescência e de ser escravo e primitivo; logo, as condições atávicas morfológicas ditavam uma regra para o crime e a punição - na maioria das vezes a forca era a solução. Arthur Ramos, no entanto, deu ênfase aos conceitos da psicanálise para elevar o sujeito na categoria de sua singularidade e estabelecer razões de um cientificismo nas relações de parentalidade, não se fixando na hereditariedade e na moral (como era o viés interpretativo na higienização psiquiátrica no momento).

As formulações propostas por Arthur Ramos, ao unir as correntes conceituais da psicanálise e da antropologia forjando o inconsciente folclórico, proporcionaram uma dimensão necessária do entendimento do Negro no Brasil, elevando essa categoria do sujeito à condição de sua estrutura psíquica, sua singularidade e sua relação com o laço social. É evidente que esse percurso teve percalços de oposição e afastamento de 
engajamento, visto que rompeu com a escola da qual foi fiel escudeiro, ao se opor a Raimundo Nina Rodrigues, permitindo-se construir um novo dispositivo de análise no qual a raça, as relações sociais e a estrutura psíquica pudessem elevar o Negro à categoria de sujeito.

Ao empregar a palavra sujeito, fazemos voz àquilo de que, na contemporaneidade, ainda somos herdeiros e reféns: uma modalidade discursiva na qual estão implícitas as noções de um substrato da miscigenação e da degenerescência. Este artigo deteve-se na discussão de um aspecto: o percurso de pesquisa de Arthur Ramos e suas relações com a loucura, em estudos que evidenciaram a situação abastardada e sórdida do brasileiro que teve a infelicidade de ser portador dos três pês: pobre, psicótico e preto (COSTA, 1989).

A noção de paranoia constitui o mote para programar nas anormalidades coletivas o fator determinante de que o Negro se torna autor e coautor desse tipo de transgressão. O histórico da paranoia, dada pela concepção da psicopatologia psiquiátrica no início do século $X X$, em particular na psiquiatria alemã, enfatizava que ela abrangia mais ou menos inteiramente as loucuras - setenta porcento dos doentes dos manicômios portavam a etiqueta paranoia.

Tudo o que chamamos psicose ou loucura era paranoia (LACAN, 1988), portanto, o discurso da psiquiatria no Brasil teve um papel relevante no processo do saber, do poder e da polícia. Pelo fato de não haver limite entre a constituição do sujeito e de seus atos, o Negro, em particular, foi colocado na forma de discurso mais reacionário: encaravam suas anormalidades sob o viés organicista, surgido como o mais conservador, o mais reacionário, o mais massacrante.

O discurso organicista, de maneira insofismável, possui como meio de sua produção o asilo, prendendo-se à regra da tradição do pensamento médico, cujo objeto apresenta-se no corpo sem vida, o cadáver. A psiquiatria tencionava se legitimar frente à comunidade médica, conforme encontramos nos artigos e/ou textos publicados desde as décadas de 1910, 1920 e 1930. Assim, essa aspiração persistiu e atualmente se acha em pleno uso, continuado através do abuso dos psicotrópicos. O excesso de prescrição medicamentosa representa não apenas a subserviência da psiquiatria aos grandes grupos da farmacologia, mas, sem dúvida, a subserviência do olhar do médico tanto antes dos primórdios da psiquiatria no Brasil como na atualidade (COSTA, 1989).

Nessa ordem dos discursos, o preventivo será aquele a reduzir o sujeito ao corpo, o sujeito à massa. São os loucos a perambular pela cidade; os improdutivos, que 
não podem trabalhar - o Negro após a escravatura se viu nessa condição, não era letrado e tampouco possuía habilidade, a não ser a única coisa que lhe deram: ser escravo -, e que nos anos 1920 e 1930 assentava-se sobre os negros e mestiços abastardados, consequentemente com problemas mentais e inaptos socialmente pelo fato de pertencerem a uma raça inferior. A higienização, um fator que abordamos neste trabalho, agora aconteceria pela incidência da prevenção em afastar qualquer influência que essa gente diferenciada pudesse agregar à burguesia em ascendência no Brasil. $\mathrm{Na}$ atualidade, o cenário não mudou. Apenas outros agentes se fazem atuantes.

Finalmente, podemos agora traçar o que constituiu e constitui o manejo de uma prática discursiva chamada de psicoterapêutica; implantada no Brasil a partir do surgimento da prática da medicina mental privada, quando surgiram os primeiros consultórios, espaços nos quais a teoria será de outra ordem, e não mais a teoria da castração e prevenção da proliferação de mestiços. No consultório, o discurso focará na família e na normalização, em razão da classe média que se formava no país na fase de industrialização; a periferia produziu efeitos de subjetivação, um dos quais a fabricação do intimismo psicológico.

O mesmo psiquiatra que dava conselhos psicoterápicos carinhosos às famílias de classe média, em outra revista era capaz de fazer coro aos que pediam a proibição do emigrante ou imigrante por considerá-los raças de degenerados, indo além: apoiando o controle de natalidade para barrar o perigo de a plebe brasileira gerar filhos e transformar o Brasil num imenso nordeste (COSTA, 1989).

Essas relações ainda subsistem na contemporaneidade, no Negro e tudo o que se possa desdobrar desse estigma, ou seja, as condições de uma paranoização do excluído por causa de cor, raça, físico, classe social ou simplesmente todos aqueles a quem as relações de poder acham necessário pôr de lado a fim de garantir sua forma de gozo na Europa. Nesse sentido, a imigração reflete-se como um espelhamento disso: são pessoas de outras civilizações que, ao se confrontar com os padrões europeus, são vistas como pertencentes a um primitivismo, degeneradas pelo atraso, que apenas querem gozar daquilo que o cidadão europeu acredita que somente ele tornou-se capaz de produzir.

Reproduzimos cenários nos quais as condições expostas nesse ártico são as mesmas que consideraram a degenerescência e a miscigenação como pretexto para usar como força de poder frente aos que são prejulgados como selvagens retrógados e inaptos a não progredir nesse universo. Mas a colonização e a alienação agora 
ocorrem pela via do poder econômico e pelo esvaziamento do sujeito como agente de escolha: o sujeito mostra-se esvaziado do discurso que o eleve à categoria do mais gozar.

Nesses aspectos nos quais expusemos a noção de uma trajetória da escravatura no Brasil, as consequências de se atribuir ao Negro o caráter de um sujeito fadado à degenerescência e o que dele se decantou pela via da miscigenação: o crime e a punição marcados antes e depois da Abolição nos trazem na contemporaneidade um retrato ao qual ainda implacavelmente vincula-se a ascensão social de uma classe e também do Negro, em que a violência representa um artifício no sentido de barrar, excluir ou eliminar essa gente diferenciada. Sob essa perspectiva, ser negro é ser violento de forma constante, contínua e cruel, sem pausa ou repouso, por uma dupla injunção: a de encarar o corpo e os ideais do EU do sujeito branco e a de recusar, negar e anular a presença do corpo negro (COSTA apud SOUZA, 1983).

Não devemos confundir o Ideal do EU com o EU Ideal: o Ideal do EU é do domínio Simbólico. Simbólico quer dizer articulação e vínculo, o registro ao qual pertencem a Ordem simbólica e a Lei que fundamenta essa ordem. Portanto, o Ideal do EU é a instância que estrutura o sujeito psíquico, vinculando-o à Lei e à Ordem. É o lugar do discurso, a estrutura mediante a qual se produzirá a conexão da normatividade libidinal com a cultura (SOUZA, 1983).

O contexto no qual o Negro se insere mostra que o Ideal do EU do Negro se apresenta em contraposição com o do branco, pois é forjado desrespeitando aquilo que, em linguagem psicanalítica, denominamos as regras de identificação normativas ou estruturantes. Essas regras são aquelas segundo as quais se permite ao sujeito ultrapassar a sua fase inicial do desenvolvimento psíquico, no qual se forja o perfil de sua identidade, desenhado a partir de uma dupla perspectiva. A primeira, o olhar e o desejo do lugar da função materna; a segunda, da imagem corporal, produto imaturo do aparelho perspectivo da criança. Se essa etapa representa o narcisismo na construção da identidade, por sua vez, requer que as regras das identificações normativas ou da estrutura possam ser uma barreira contra a perpetuação dessa posição originária da infância do homem (SOUZA, 1983).

A paranoização ou a paranoia do Negro no Brasil na ótica de Arthur Ramos representa seu esforço de construir um conceito de inconsciente folclórico que pudesse melhor entender a lógica do pensamento estruturante do Negro e suas relações de identificação, visto que o sujeito inserido na ordem da linguagem desde sempre e as 
condições estruturantes apontam, em seu desenvolvimento psíquico infantil, o acesso a outra ordem do existente: a ordem da cultura, na qual o discurso e o desejo materno não mais serão as únicas fontes de definição da "verdade" ou "realidade" de sua identidade.

Contudo, na contemporaneidade esse legado de Arthur Ramos nos possibilita pensar uma condição de estratégia clínica implicada, em que o Negro possa ter voz e lugar para seu Mal-estar estrutural, psíquico e social. Nesse sentido, podemos ofertar uma proposta: como seria possível construir um dispositivo clínico psicanalítico que pudesse levar em consideração as nuances da identificação do Negro no Brasil em um processo de transformação frente a problemática da paranoia social, na construção de uma tática, uma estratégia e uma política imbricadas nas manifestações da patologia social?

Julgo necessário esclarecer a noção de patologia social, para que possa também ter o cunho de uma paranoia, nesse caso implicada na estimação do Negro e suas relações com o branco. Levarei em consideração a proposta de Safatle (2018, p. 11) com a seguinte expressão:

[...] falar em patologia social envolve uma reflexão sobre as patologias enquanto categorias que descrevem modos de participação social, e não uma reflexão sobre a sociedade como organismo saudável ou doente. Isso permite uma reflexão e desenvolvimento entre a clínica e a crítica no interior da qual a crítica social aparece indissociável do diagnóstico de limitação do campo de experiência implicado na circulação massiva de quadros de patologias, na transformação reiterada de sofrimento em patologias específicas. A desconstituição da aparência de naturalidade de tais patologias pode reconduzir o sofrimento à condição de matriz produtora de singularidade. Tal compreensão de categorias clínicas como categorias sociais nos leva inicialmente a questões epistemológicas vinculadas ao campo do saber psiquiátrico e psicológico

Assim, as epistemologias vinculadas do saber psiquiátrico - Michel Foucault -, a psicanálise - Freud, Lacan - e a antropologia - Lévi-Strauss - seria um processo de transformação a dar ao sujeito o suporte de inserção no laço social. 


\section{REFERÊNCIAS}

BARRoS, C. O. L. (Coord). Memória do Saber - Arthur Ramos. Rio de Janeiro: Fundação Miguel de Cervantes, 2010.

COSTA, F. J. História da Psiquiatria no Brasil - um corte ideológico. Rio de Janeiro: Xenon, 1989.

FREUD, S. [1912-1913] Totem e Tabu. In: FREUD, Sigmund. Obras Completas volume 11. Trad. Paulo César de Souza. São Paulo: Companhia das Letras, 2012.

FREUD, S. [1914] Introdução ao Narcisismo. In: FREUD, Sigmund. Obras Completas volume 12. Trad. Paulo César de Souza. São Paulo: Companhia das Letras, 2010.

FREUD, S. [1921] Psicologia das Massas e Análise do Eu. In: FREUD, Sigmund. Obras Completas volume 15. Trad. Paulo César de Souza. São Paulo: Companhia das Letras, 2000.

FREUD, S. [1893 -1899] A Hereditariedade e a Etiologia das Neuroses. In: FREUD, Sigmund. Obras Psicológicas Completas. v. III. Rio de Janeiro: Imago, 2006.

FOUCAUlT, P, M. O Poder Psiquiátrico. São Paulo: Martins Fontes Editora, 2006.

FANON, F. Os Condenados da Terra. Rio de Janeiro: Civilização Brasileira, 1968.

LACAN, J. Introdução teórica às funções da psicanálise em criminalidade. In: LACAN, Jacques. Escritos. Trad. Vera Ribeiro. Rio de Janeiro: Jorge Zahar Editor, 1998.

LACAN, J. As psicoses (1955-1956) - seminário (livro 03). Trad. Aluísio Menezes. Rio de Janeiro: Jorge Zahar Editor, 1988.

LACAN, J. O avesso da psicanálise (1969-1970) - seminário (livro 17). Trad. Ari Roitman. Rio de Janeiro: Jorge Zahar Editor, 1992.

PEREIRA, C. E. M. Morel e a questão da degenerescência, São Paulo, Revista Latinoamericana de Psicopatologia Fundamental, v. 11, n. 3, p. 490-496, 2008.

PRADO, Paulo. Retrato do Brasil. São Paulo: Companhia das Letras, 2001.

PRADO JUNIOR, Caio. História econômica do Brasil. São Paulo: Brasiliense, 1980.

ODA, Ana Maria G. R.; DALGALARRONDO, Paulo. Uma preciosidade da psicopatologia brasileira: A paranoia nos negros, de Raimundo Nina-Rodrigues, São Paulo, Revista Latinoamericana de Psicopatologia Fundamental, ano VII, n.2, jun. 2004. Disponível em: $<$ http://www.redalyc.org/comocitar.oa?id=233017780009>. Acesso em: out. 2019.

OLIVEIRA, C. R. Razão e afetividade - o pensamento de Lucien Lévy-Brühl, Brasília: Biblioteca Central da Universidade de Brasília, 2002. 
RAMOS, A. Primitivo e loucura. Tese (Doutorado). Bahia: Imprensa Oficial do Estado, 1926.

RAMOS, A. Introdução à Psicologia Social. Rio de Janeiro: Livraria Editora da Casa do Estudante no Brasil, 1957.

RAMOS, A. Loucura e Crime. Porto Alegre: Globo, 1937.

RAMOS, A. O negro na civilização brasileira. Rio de Janeiro: Livraria Editora da Casa do Estudante no Brasil, 1971.

RAMOS, A. Os Grandes Problemas da Antropologia Brasileira. Rio de Janeiro: Catálogo Arquivo Arthur Ramos Inventário, 2004. [Biblioteca Nacional, n. 4247, referência pastas 04, 09, 38].

RODRIGUES, N. R. Atavismo psíquico e paranoia [1902] (2009). Revista Latino-americana de Psicopatologia Fundamental. São Paulo, v. 12, n. 4, p. 766-789, dez. 2009.

SOUZA, S. N. Tornar-se Negro. Rio de Janeiro: Graal, 1983.

SOILO, A. N. Do evolucionismo clássico ao particularismo histórico na antropologia: principais ideias. Pelotas, Revista Tessituras, v. 2 n. 1, p. 251-261, jan./jun.2014.

SAFATLE, V.; JUNIOR S. N.; DUNKER, C. Patologia do social - Arqueologia do sofrimento psíquico. Belo Horizonte: Autêntica, 2018.

SCHWARCZ, M. L.; GOMES, F. Dicionário da Escravidão e Liberdade. São Paulo: Cia das Letras, 2018. 


\title{
The Paranoia of the Black in BRAZIL, the ANALysis OF \\ ARTHUR RAMOS: A RELATIONSHIP BETWEEN IDENTIFICATION, Crime and Punishment
}

\begin{abstract}
This article, we propose to expose and discuss the theoretical construction of alagoas physician and psychiatrist arthur ramos de araújo pereira (1903-1940), who established relationships between degeneration and miscegenation factors in negro paranoia in brazil, interrelated with the process of identification, crime and punishment. in a first moment following the school founded by maranhão doctor raimundo nina rodrigues (1862-1906), professor of the bahia medical school, in which the process of mental abnormalities resided in the miscegenation factor, that is, the inbreeding between blacks, indians, and degeneration. factors of violence and consequence-based crime would be attributed in which the conditions of degeneracy, cesar lombroso's (18351909) theoretical proposal and the atavistic theory of tanzi and riva, gave the negro a paranoid mental abnormality character where the conditions of crime and violence would be directly linked. in tracing in this article the theoretical aspects given by arthur ramos in the concept of negro paranoia and its relation to crime and punishment, his attempts to emphasize not only the uniqueness of the negro, but to formulate the concept of the folkloric unconscious. a question will be part of this work; under what condition in contemporary times it would still be possible to take into account the conditions of the negro in brazil and the relationship of paranoia as a social catastrophe, between the constitution of paranoia as a clinical category and the social aesthetic experience of crisis, that is, of transformation.
\end{abstract}

KEYWORDS: Degeneration. Miscegenation. Paranoia. Negro. Psychoanalysis. 


\section{LA PARANOÏE DES NOIRS AU BRÉSIL, L'ANALYSE D'ARTHUR Ramos: une Relation Entre Identification, Crime et Peine}

\section{RÉSUMÉ}

Rédaction et promotion du traitement de la qualité de la médecine et de la reproduction des droits de l'homme Arthur Ramos de Araújo Pereira (1903-1940), qui est actuellement en vente dans d'autres régions du monde. Processus d'identification, crime et punition. Cliquez ici pour afficher le récit de la fondation Raimundo Nina Rodrigues (1862-1906), professeur à la faculté de médecine de Bahia, en ce qui concerne le traitement des résidences anormales et traditionnelles, ainsi que la tradition et la tradition brancos e Índios, ea degenerescência. Seria atribuído fatores of violência and crime theada em ples da it as a condíçes da degenerescência, proposta teórica de Cesar Lombroso (1835-1909); violência seriam diretamente vinculados. Vos remarques sur les aspects de la vie de Arthur Ramos ne sont pas paranoïaques et négatives, mais nous vous invitons également à voter, à vous identifier, à vous identifier, à vous identifier, à vous identifier, à vous identifier, à vous identifier et à personnaliser votre blog. Uma pergunta fara parte desse trabalho; dans les conditions actuelles et potentielles, ils peuvent être considérés comme un peuple noir et une relation sociale avec un groupe social, entre une catégorie de médicaments et une expérience sociale, une crise sociale, une transformation, des événements sociaux.

Mots-CLÉs: Dégénérescence. Métissage. Paranoïa. Noir. Psychanalyse. 
RECEBIDO EM 21/04/2020

APROVADO EM 10/10/2020

(C) 2020 Psicanálise \& Barroco em revista

http://www.seer.unirio.br/index.php/psicanalise-barroco/index

revista@psicanaliseebarroco.pro.br

Programa de Pós-Graduação em Memória Social — UNIRIO

Memória, Subjetividade e Criação

www.memoriasocial.pro.br/proposta-area.php 